\title{
Retinoid $N$-(1H-benzo[d]imidazol-2-yl)-5,5,8,8-tetramethyl-5,6,7, 8-tetrahydronaphthalene-2-carboxamide induces p21-dependent senescence in breast cancer cells
}

\author{
Mine Mumcuoglu ${ }^{\mathrm{a}, \mathrm{b}}$, A. Selen Gurkan-Alp ${ }^{\mathrm{c}}$, Erdem Buyukbingol ${ }^{\mathrm{c}}$, Rengul Cetin-Atalay ${ }^{\mathrm{a}, \mathrm{d}, *}$ \\ a LOSEV the Foundation for Children with Leukemia, Cancer Genetics Research Laboratory, Ankara, Turkey \\ ${ }^{\mathrm{b}}$ Department of Molecular Biology and Genetics, Bilkent University, Bilkent, 06800 Ankara, Turkey \\ ${ }^{\mathrm{c}}$ Department of Pharmaceutical Chemistry, Faculty of Pharmacy, Ankara University, Turkey \\ ${ }^{\mathrm{d}}$ Graduate School of Informatics, Cancer Systems Biology Laboratory, METU, 06800 Ankara, Turkey
}

\section{A R T I C L E I N F O}

Article history:

Received 26 September 2015

Received in revised form 20 January 2016

Accepted 11 February 2016

Available online 17 February 2016

\section{Keywords:}

Retinoid

Cytotoxicity

Breast cancer

Senescence

RXR

\begin{abstract}
A B S T R A C T
Retinoids have been implicated as pharmacological agents for the prevention and treatment of various types of cancers, including breast cancers. We analyzed 27 newly synthesized retinoids for their bioactivity on breast, liver, and colon cancer cells. Majority of the retinoids demonstrated selective bioactivity on breast cancer cells. Retinoid $\mathbf{1 7}$ had a significant inhibitory activity $\left(\mathrm{IC}_{50} 3.5 \mu \mathrm{M}\right)$ only on breast cancer cells while no growth inhibition observed with liver and colon cancer cells. The breast cancer selective growth inhibitory action by retinoid $\mathbf{1 7}$ was defined as p21-dependent cell death, reminiscent of senescence, which is an indicator of targeted receptor mediated bioactivity. A comparative analysis of retinoid receptor gene expression levels in different breast cancer cells and $\mathrm{IC}_{50}$ values of $\mathbf{1 7}$ indicated the involvement of Retinoid X receptors in the cytotoxic bioactivity of retinoid $\mathbf{1 7}$ in the senescence associated cell death. Furthermore, siRNA knockdown studies with RXR $\gamma$ induced decrease in cell proliferation. Therefore, we suggest that retinoid derivatives that target $\operatorname{RXR} \gamma$, can be considered for breast cancer therapies.
\end{abstract}

(c) 2016 Elsevier Inc. All rights reserved.

\section{Introduction}

Vitamin A and its synthetic and naturally occurring derivatives, known as retinoids, are essential in embryonic development and in the maintenance of physiological processes involving vision, metabolism, cellular homeostasis and the growth and differentiation of many tissues [1-3]. Retinoid signaling also plays an important role in carcinogenesis in transformed cells [4]. Animal experiments, cellular models and clinical trials have supported the idea of using retinoids as chemopreventive and chemotherapeutic agents [5]. All-trans-retinoic acid (ATRA), as the most-active metabolite, has

Abbreviations: ATRA, all-trans-retinoic acid; CDK, cyclin-dependent kinase; ER, estrogen receptor; RA, retinoic acid; OIS, oncogene-induced senescence; PICS, PTEN-loss induced cellular senescence; SRB, Sulforhodamine B; SABG, senescenceassociated $\beta$-galactosidase; siRNA, small interfering RNA; $\mathrm{IC}_{50}, 50 \%$ growthinhibitory concentration; $\mathrm{IC}_{100}, 100 \%$ growth-inhibitory concentration; RAR retinoic acid receptor; RXR, Retinoid X receptor; SERMs, selective ER modulators; TNBC, triple-negative breast cancer; SCP, senescent cell progenitor.

* Corresponding author at: Graduate School of Informatics, Cancer Systems Biology Laboratory, Middle East Technical University, ODTU, 06800 Ankara, Turkey.

E-mail address: rengul@metu.edu.tr (R. Cetin-Atalay). been reported to affect diverse biological activities, including breast cancer [6]. ATRA inhibits cell growth in cancer cells by blocking the G1 phase of the cell cycle [7,8]. G1 arrest is induced by the induction of cyclin-dependent kinase (CDK) inhibitors such as p21 and p16 in the presence of ATRA $[9,10]$. CDK inhibition by p21 causes dephosphorylation of the retinoblastoma protein, $R b$, leading to the inhibition of the E2F transcription factor. Consequently, target genes involved in cell cycle progression and cell proliferation are down-regulated [11]. It has been recently shown that ATRA induces cellular senescence in HepG2 cells through p21 and p16, and in MCF7 cells only with p21 activation [12].

Breast cancer is the second most common cancer worldwide and it affects about one in 10 women [13]. As a consequence of the aging of world populations, this disease is a major public health problem. Previously, breast cancer was considered a disease of women in developed countries only, but incidence and mortality rates have been increasing in less-developed countries in recent years [13]. In spite of the many developments in early diagnostic and therapeutic strategies, breast cancer is still a major obstacle. It is a heterogeneous disease and is classified into luminal, 
basal-like, normal-like and ERBB2-positive subtypes. Estrogenreceptor (ER)-positive breast cancer cells produce senescent progeny, and this ability is correlated with ER loss and p21 accumulation [14]. Several studies have shown that retinoic acid (RA) inhibits cell growth, especially in estrogen-receptor-positive breast cancer cells, by either apoptosis or cell cycle arrest $[15,16]$. Retinoids have been explored as therapeutic and preventive agents in different cancer types [17-19]. In breast cancer, retinoids, especially fenretinide (4-HPR), have been investigated as preventive agents in various clinical trials [20].

Most anti-cancer agents inhibit growth by interfering with signaling pathways in cancer cells, ultimately leading to apoptosis. Recent studies indicate that drug-dependent senescence is a promising mechanism that may advance cancer therapy $[21,22]$. During cellular senescence, cells grow old and die due to aging. Involving novel chemotherapeutic candidates in reprogramming cell senescence is an important approach in the realm of cancer treatment. Normally replicative senescence observed due to telomere shortening during replication whereas the molecular analysis of senescence in cancer cells demonstrated oncogene-induced senescence (OIS) and PTEN-loss induced cellular senescence (PICS) mechanisms [23-25]. Based on these findings and due to the prolonged activity of retinoids in the cell, we submit that these compounds be further exploited as senescence-associated antiproliferative agents in chemotherapeutic regimes.

In this study, we tested previously synthesized retinoid derivatives [26] for their cytotoxicity in a series of breast cancer cell lines. We then further studied compound 17, which showed the most anti-proliferative activity, to identify its mechanism of action at the molecular level.

\section{Experimental}

\subsection{Cell culture}

The breast cancer cell lines (Cama-1, T47D, MCF7, BT-474, MDA-MB-453, BT-20, SK-BR-3, MDA-MB-361, MDA-MB-157, MDA-MB-231 and MCF-12A) were obtained from ATCC. All breast, Huh7 liver and HCT116 cells were authenticated by STR analysis regularly. T47D, BT-474, MCF-7, BT-20, MDA-MB-453, MDA-MB231 and Huh7 were grown in Dulbecco's modified Eagle's medium (DMEM). Cama-1 and MDA-MB-157 were cultivated in DMEM supplemented with $1 \%$ sodium pyruvate. SK-BR-3 was cultivated in RPMI (glucose rich; $4.5 \mathrm{~g} / \mathrm{L}$ ) medium (Sigma). Unless indicated all media had phenol red and supplemented with 10\% FCS and $50 \mathrm{mg} / \mathrm{ml}$ penicillin-streptomycin for both retinoid treated and control experiments. Compound $\mathbf{1 7}$ was further tested in phenol red free medium in order to validate its cytotoxic activity in T47D cells. This study does not involve animals or human volunteers therefore ethics approval is not required.

\subsection{Preparation of the compounds}

Retinoids were kept in powder form at dark $4{ }^{\circ} \mathrm{C}$ and they were dissolved in Dimethyl sulfoxide (DMSO) with a concentration of $20 \mathrm{mM}$ the stock solution of the compounds were prepared and kept in $-20^{\circ} \mathrm{C}$ during the experiments. For SRB assay concentration curve from $40 \mu \mathrm{M}, 20 \mu \mathrm{M}, 10 \mu \mathrm{M}, 5 \mu \mathrm{M}$ to $2.5 \mu \mathrm{M}$ were used. For other experiments the concentrations were used as indicated in the figure legends. The retionids were prepared from the stock solutions prior to the experiments. Because retionids are light sensitive, compounds were always kept in dark and experiments were done under dim light.

\subsection{Sulforhodamine B (SRB) cytotoxicity assay}

Retinoids were tested with an National Cancer Institute (NCI) anticancer drug screening method for their growth-inhibitory activity [27]. The cells (10,000 cells/well) were seeded into 96-well plates in $200 \mu \mathrm{l}$ of medium $24 \mathrm{~h}$ prior to treatment with retinoids. After $72 \mathrm{~h}$ of treatment with retinoids, the cells were fixed by $60 \mu \mathrm{l}$ of cold TCA $(10 \%(\mathrm{w} / \mathrm{v}))$ for $60 \mathrm{~min}$ at $4{ }^{\circ} \mathrm{C}$. Then $100 \mu \mathrm{l} 0.4 \%$ SRB solution was applied and the cells were incubated for $10 \mathrm{~min}$ at room temperature. Unbound dye was washed five times with $1 \%$ acetic acid and air dried. An SRB dye solubilized by $10 \mathrm{mM}$ TrisBase solution and absorbance were acquired at $515 \mathrm{~nm}$. Absorbance values of DMSO only treated wells, which were controls, were used for normalization. $50 \%$ growth-inhibitory concentration $\left(\mathrm{IC}_{50}\right)$ values were calculated as described in [28].

\subsection{Senescence-associated $\beta$-galactosidase (SABG) assay}

T47D cells were seeded onto coverslips in 12-well plates as 7500 cells/well. After $24 \mathrm{~h}$ compound 17 was added to the wells as at IC50 $(3.7 \mu \mathrm{M})$ and IC100 $(7.4 \mu \mathrm{M})$ levels. Control wells were treated with only DMEM or same drug level of DMSO. Every $48 \mathrm{~h}$ cell culture medium and the drug was replenished. Experiments were stopped at 2th, 4 th and 6th days of treatment and then SABG assay was performed. Experiments were generated as a triplicate for each condition [29]. Cells were counterstained with nuclear fast red following SABG staining. SABG positive and negative cells from each condition were counted under the light microscope from randomly selected areas and percentages were calculated for SABG positive and negative cells.

\subsection{Western blot analyzes}

Upon treatment with compound 17, cell pellets were incubated in an NP-40 lysis buffer (50 mM Tris-HCl, pH 8.0, $250 \mathrm{mM} \mathrm{NaCl}$, $0.1 \%$ Nonidet P-40) and a protease-inhibitor cocktail (Roche) for $30 \mathrm{~min}$ at $4{ }^{\circ} \mathrm{C}$. Bradford assay was performed to quantify the protein concentration of the cell lysates. $30 \mu \mathrm{g}$ of protein was denatured and resolved by SDS-PAGE using $10 \%$ gel. Then the proteins were transferred to the nitrocellulose membranes. Membranes were treated for $1 \mathrm{~h}$ with blocking solution (TRIS-buffered saline containing $0.1 \%$ Tween-20 and $5 \%$ non-fat milk powder (TBS-T)) and probed with a primary antibody for $1 \mathrm{~h}$. Next, membranes were washed three times with TBS-T and incubated with an HRP-conjugated secondary antibody for $1 \mathrm{~h}$. Then immune complexes were detected by an ECL-plus (Amersham) kit. Calnexin and Actin were used for equal loading control. The following antibodies were used in this study: anti-p21Cip1 (OP64; Calbiochem), Rb (BD Bioscience, 554136), phospho-Rb (Ser 807/811) (Cell Signaling, 9308S), Calnexin (Sigma, C4731) and Actin (Santa Cruz, sc1616).

\subsection{RNA extraction, $C D N A$ synthesis and semiquantitative $R T-P C R$}

Total RNA was extracted from cultured cells with a Nucleo Spin RNA II Kit (MN Macherey-Nagel, Duren, Germany) according to the manufacturer's protocol. Two micrograms of total RNA were reverse transcribed into cDNA in a total volume of $20 \mu \mathrm{l}$ using a Revert Aid First Strand cDNA synthesis kit (MBI Fermentas, Vilnius, Lithuania). The PCR reactions were carried out with $1 \mu$ l of cDNA, using the appropriate number of cycles and annealing temperature (Tm). Annealing temperatures (Tm) and cycle numbers were optimized for each transcript. The PCR conditions were: RAR- $\alpha$; Tm: $55^{\circ} \mathrm{C}, 30$ cycles, RAR- $\beta$; Tm: $60^{\circ} \mathrm{C}, 30$ cycles, RAR- $\gamma$; Tm: $60^{\circ} \mathrm{C}, 32$ cycles, RXR $\alpha$ and RXR $\beta$; Tm: $58^{\circ} \mathrm{C}, 30$ cycles, RXR $\gamma ; \mathrm{Tm}: 62^{\circ} \mathrm{C}, 35$ cycles. The primer sequences were: RAR- $\alpha$ F-5'GAGCCGGTCCTTTGGT CAA3', R-5'CTGCGAGCATCACAGGACAT3', RAR- $\beta$ F-5'ATTCCAGTGC 
TGACCATCGAGTCC-3', R-5'CCTGTTTCTGTGTCATCCATTTCC3', RAR$\gamma$ F-5'TACCACTATGGGGTCAGC3', R-5'CCGGTCATTTCGCACAGCT3' RXR $\alpha$, F-5'TTCGCTAAGCTCTTGCTC3', R-5'ATAAGGAAGGTGTCAAT GGG3' RXR $\beta$, F-5'GAAGCTCAGGCAAACACTAC3', R-5'TGCAGTCTTT GTTGTCCC $3^{\prime}$ RXR $\gamma$, F-5'GCAGTTCAGAGGACATCAAGCC $3^{\prime}$ and R-5'GCCTCACTCTCAGCTCGCTCTC-3'. PCR products were analyzed on a $2 \%$ agarose gel and visualized with ethidium bromide under UV transillumination. The mRNA bands were quantified by the Image J program (http://imagej.nih.gov).

\section{7. siRNA transfection}

siRXR $\alpha$ (Dharmacon) and siRXR $\gamma$ (Invitrogen) were transfected into MCF7 cells by using the "reverse transfection" method according to the manufacturer's guidelines. siRNA silencing was then confirmed by RT-PCR semiquantitative RT-PCR analysis.

\subsection{Statistical analysis}

Statistical analysis was carried out with StatPlus:mac software (AnalystSoft). Statistical differences between two groups were determined using the student's $t$ test, and between all groups were determined with an analysis of variance (ANOVA) test with a Bonferroni adjustment. $p$ values of $<0.05$ or $p<0.01$ were accepted as statistically significant.

\subsection{Static docking}

The coordinate files of the human retinoic acid receptors $\mathrm{RXR} \gamma$ and RXR $\alpha$ ligand-binding domains (pdb ID: 2GL8 and 1FBY) were prepared for docking with the UCSF Chimera tool, a visualization system for exploratory research and analysis [30]. The Chimera Dock Prep tool was used to delete water molecules, to add hydrogen and to write the file in Mol2 format from the homotetramer $\mathrm{RXR} \gamma$ structure. A 3D structure of compound $\mathbf{1 7}$ was prepared in Mol2 format with Marvin Sketch (http://www.chemaxon.com) and the retinoic acid structure was acquired from Protein Data Bank (pdb ligand ID: REA). Docking between RXRs and compound 17 was performed on the SwissDock server based on EADock DSS [31,32]. Binding modes were analyzed using the Chimera tool; the docked 2GL8 for $\operatorname{RXR} \gamma$ and 1FBY for RXR $\alpha$ are shown in Fig. 5.

\section{Results}

\subsection{Cytotoxic activity of retinoids in cancer cells}

Twenty-seven newly synthesized retinoid derivatives [26], $\mathrm{N}$-(3,5,5,8,8-pentamethyl-5,6,7,8-tetrahydronaphthalene-2-yl)-carboxamides (6-15) and 5,5,8,8-tetramethyl-5,6,7,8-tetrahydronaphthalene-2-carboxamides (16-32) were screened for their cytotoxic activity in cancer cells by the SRB assay. T47D breast, Huh7 liver and HCT116 colon cancer cells were treated with the compounds and with ATRA, and their IC $_{50}$ values were determined (Supplementary Table 1 and Supplementary document 1 ).

The cytotoxicity induced by the compounds was prominent in T47D cells. The compounds with the lowest $\mathrm{IC}_{50}$ concentrations $(6,8,10,11,17,18,24,25,26$, and 27), were selected to be further analyzed for their anti-proliferative activity on a larger panel of breast cancer cells and on an MCF-12A immortalized normal breast epithelial cell line (Table 1 and Supplementary document 2). Compounds 6, 8, 10 and 11 have been previously synthesized as derivatives of $N$-(3,5,5,8,8-pentamethyl-5,6,7,8-tetrahydronaphthalene-2-yl)-carboxamides, compounds 17, 18, 24, 25, 26 and 27 have been synthesized as derivatives of 5,5,8,8-tetramethyl- 5,6,7,8-tetrahydronaphthalene-2-carboxamides [26]. Camptothecin, which is a potent cytotoxic agent, was included as an experimental positive control (Table 1).

The selected compounds had heterogeneous cytotoxic actions on breast cancer cell lines. Compounds $\mathbf{1 7}$ and $\mathbf{2 4}$ had the lowest $\mathrm{IC}_{50}$ values in certain cell lines (Table 1 ). The cytotoxicity of compound 24 was more specific on BT-20 cell lines, while compound 17 exhibited broader cytotoxic activity on breast cancer cells. The 50\% growth-inhibitory concentration of compound $\mathbf{1 7}$ on MCF-12A, which is the immortalized normal breast epithelial cell line, was fivefold higher than that of T47D. Additionally, in a previous study, compound $\mathbf{1 7}$ was found to be non-toxic normal human macrophage cells [26]. Therefore, compounds $\mathbf{1 7}$ and $\mathbf{2 4}$ are considered good cytotoxic agent candidates for the treatment and prevention of breast cancer. Compound $\mathbf{1 7}$ had no cytotoxic action on the Huh7 liver and HCT116 colon cells (Supplementary Table 1). Based on these observations, we focused our studies on the cytotoxicity induced by 17 , which showed the most breast-cancer-cell specificity within the 27 tested retinoid derivatives. We also confirmed the cytotoxic activity of retinoid $\mathbf{1 7}$ in phenol red free medium in comparison with DMSO controls on T47D cells. SRBcytotoxicity assay was performed in triplicate and $\mathrm{IC}_{50}$ value were identified as $9.8 \mu \mathrm{M}\left(R^{2}=0.9\right)$. When the $\mathrm{IC}_{50}$ value $(3.5 \mu \mathrm{M})$ in the presence of phenol red which induces mild cell proliferation, compared to this value $(9.8 \mu \mathrm{M})$, we observe that $\mathbf{1 7}$ may be more active against fast proliferating cells.

\subsection{Identifying the cell death type induced by $\mathbf{1 7}$}

To understand the molecular mechanism behind the cytotoxic effect of compound $\mathbf{1 7}$ (Fig. 1A), we first determined whether this action occurs by apoptosis. To test apoptosis induction, we performed in situ Hoechst-33258 staining, cytochrome $C$ release and PARP protein cleavage analysis (Supplementary Fig. 2) after treating T47D cells with compound $\mathbf{1 7}$. None of these apoptosis markers gave positive results.

Also observed during compound $\mathbf{1 7}$ treatments of breast cancer cells was a late cytotoxic response, which is indicative of long-term cell death induction. An anti-proliferative effect was seen after about six days of retinoid treatment. This late response led us to consider senescence-associated cell death, which is another important growth-inhibitory mechanism observed in cancer cells [33]. Therefore, we investigated whether senescence induction occurs upon treating T47D cells with compound 17. SABG staining was performed after two-, four- and six-days of treatment with 17 on T47D cells. Compound $\mathbf{1 7}$ was applied to the cells at $\mathrm{IC}_{50}$ $(3.7 \mu \mathrm{M})$ and $\mathrm{IC}_{100}(7.4 \mu \mathrm{M})$ concentrations. SABG-positive and negative cells were counted from randomly selected areas under the light microscope and the percentages of senescent cells were calculated. The $\mathrm{IC}_{100}$ concentration of $\mathbf{1 7}$ caused statistically significant senescence associated cell death compared to DMSO controls (Fig. 1B). Representative pictures of SABG staining are presented in Fig. 1C. Blue cells demonstrate SABG positivity as a result of senescence-associated cell death.

\subsection{Molecular analysis of senescence upon $\mathbf{1 7}$ treatment}

CDK inhibitor p21waf1/Cip1/Sid1 is an important mediator of p53-dependent cell cycle arrest upon DNA damage [10,34]. p21 is also one of the key regulators of senescence, and ATRA treatment causes up-regulation of p21 in different cell lines [35]. These findings motivated us to determine the involvement of the $\mathrm{p} 21-\mathrm{Rb}$ pathway in compound 17's mechanism of action. For this purpose we analyzed p21 protein levels in T47D cells treated with $\mathrm{IC}_{50}$ and $\mathrm{IC}_{100}$ concentrations of $\mathbf{1 7}$ for two, four and six days. These treatments induced a time-dependent p21 protein increase for 
Table 1

Cytotoxic activities ( $\mathrm{IC}_{50}$ in $\mu \mathrm{M}$ ) of the retinoids on breast cancer cell lines. ${ }^{\mathrm{a}}$

\begin{tabular}{|c|c|c|c|c|c|c|c|c|c|c|c|}
\hline \multirow[t]{2}{*}{ Cell lines } & \multicolumn{11}{|c|}{ Compounds } \\
\hline & 6 & 8 & 10 & 11 & 17 & 18 & 24 & 25 & 26 & 27 & $\mathrm{CPT}^{\mathrm{b}}$ \\
\hline CAMA-1 & 38.11 & 24.94 & 4.82 & 23.44 & 12.16 & 8.73 & 7.28 & 9.6 & 7.47 & 9.97 & 0.07 \\
\hline T47D & 17.3 & 12.08 & 14.93 & 16.43 & 3.71 & 6.03 & 4.08 & 10.31 & 10.5 & 8.67 & $<0.01$ \\
\hline MCF7 & 8.07 & 9.66 & 9.02 & 11.1 & 6.93 & 12.98 & 10.5 & 22.09 & 11.57 & 8.8 & $<0.01$ \\
\hline BT474 & 16.52 & 7.81 & 26.35 & 22.01 & 12.91 & 8.37 & $\mathrm{NI}^{\mathrm{C}}$ & 21.38 & $\mathrm{NI}$ & 14.54 & 12.75 \\
\hline MDA-MB-453 & 11.97 & 5.9 & 13.6 & 23.33 & 6.19 & 16.92 & 17.48 & 20.57 & 9.03 & 12.33 & $<0.01$ \\
\hline BT20 & 11.33 & 10.05 & 11.62 & 11.61 & 3.85 & 11.68 & 2.55 & 9.46 & 14.52 & 11.27 & 0.07 \\
\hline SK-BR-3 & 9.77 & 7.46 & 10.1 & 7.72 & 11.23 & 8.38 & $\mathrm{NI}$ & 18.68 & $\mathrm{NI}$ & 9.68 & $<0.01$ \\
\hline MDA-MB-361 & 11.18 & 8.58 & 9.76 & 15.07 & 11.45 & 11.06 & $\mathrm{NI}$ & $\mathrm{NI}$ & $\mathrm{NI}$ & 12.15 & 0.14 \\
\hline MDA-MB-157 & 18.81 & 19.49 & 12.85 & 16.94 & 9.77 & 22.62 & NI & $\mathrm{NI}$ & 14.21 & 7.07 & 0.02 \\
\hline MDA-MB-231 & 42.85 & 18.93 & 15.22 & 15.7 & 32.6 & 16.57 & 24.99 & $\mathrm{NI}$ & 13.32 & 12.98 & $<0.01$ \\
\hline MCF-12A & 17.93 & $\mathrm{NI}$ & 10.86 & 11.4 & 15.91 & NI & $\mathrm{NI}$ & NI & 34.62 & NI & $<0.01$ \\
\hline
\end{tabular}

Significant $\mathrm{IC}_{50}$ are indicated in bold.

a Cytotoxicities of all 27 retinoids are given in Supplementary Table 1.

b CPT: Camptothecin is used as an experimental positive control.

c NI: no inhibition.

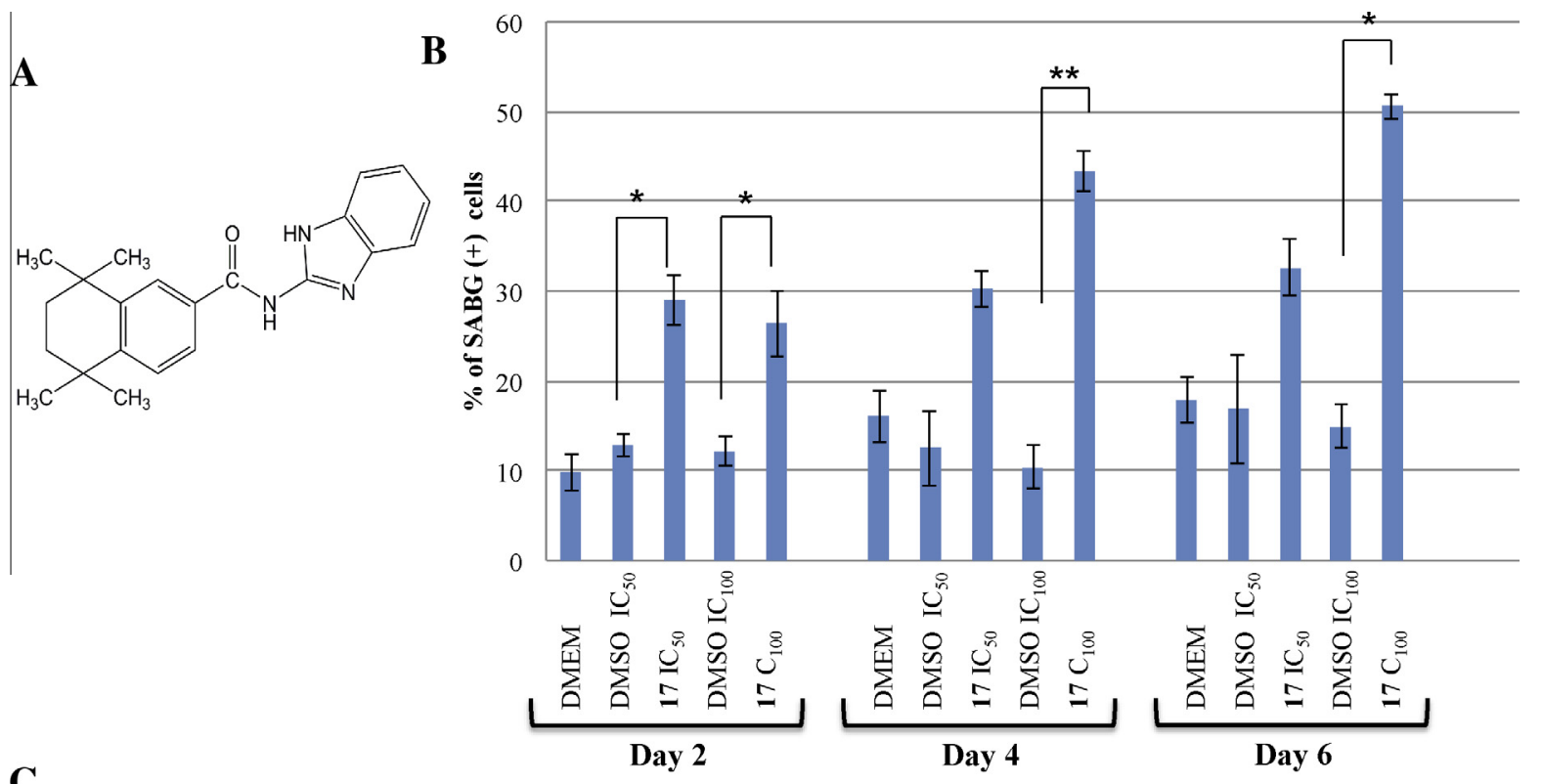

C

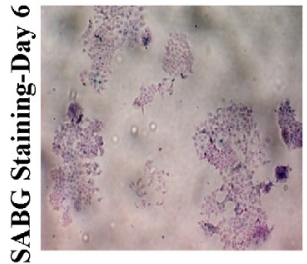

DMEM

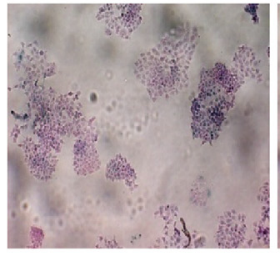

DMSO

$\mathrm{IC}_{50}$

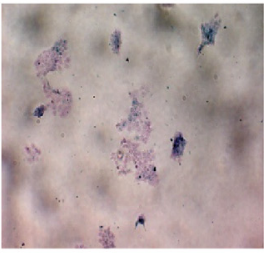

17
$\mathrm{IC}$

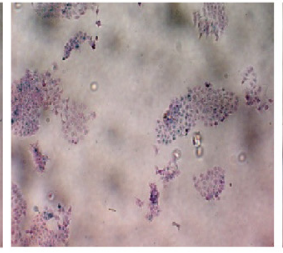

DMSO

$\mathrm{IC}_{100}$

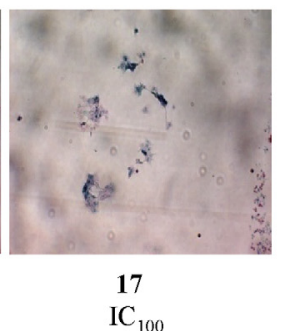

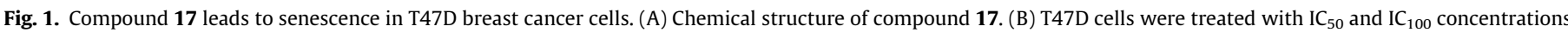

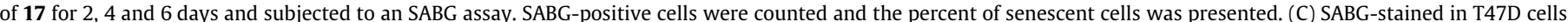
upon 6 days of treatment with $\mathrm{IC}_{50}(3.7 \mu \mathrm{M})$ and $\mathrm{IC}_{100}(7.4 \mu \mathrm{M})$ concentrations of 17. $p$-Values were calculated by paired two-tailed $t$ tests. ${ }^{*} p<0.01,{ }^{* *} p<0.005$.

both concentrations; in comparison, DMSO-treated control cells (Fig. 2).

\subsection{Correlation between retinoic acid receptors and the cytotoxicity of 17}

The variation observed in the $\mathrm{IC}_{50}$ values motivated us to further analyze the molecular mechanisms in senescence and its possible relation to RARs. Differential expressions of RAR levels in breast cancer cells might be the reason for these cells' diverse
$\mathrm{IC}_{50}$ values obtained with the retinoid derivatives (Table 1 and Fig. 3A). Retinoic acid and its synthetic derivatives (retinoids) mediate their effect through RARs and RXRs. Therefore, knowledge of RAR expression in our breast cancer cell line panel was essential in identifying the subtype-specific cytotoxicity induced by $\mathbf{1 7}$. For this purpose, the cells were characterized for their RAR and RXR status by the semi-quantitative RT-PCR method (Fig. 3 and Supplementary Fig. 3). We did not observe an association between $\mathrm{IC}_{50}$ values and RAR expression levels (Fig. 3B). Although RXR $\alpha$ and RXR $\beta$ were expressed equally in all cell lines tested, $\operatorname{RXR} \gamma$ 


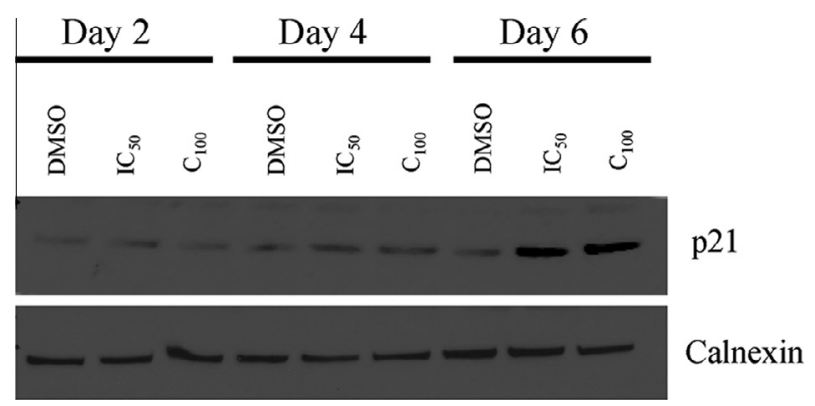

Fig. 2. Senescence-associated upregulation of p21. T47D cells were treated with compound 17 at $\mathrm{IC}_{50}(3.7 \mu \mathrm{M})$ and $\mathrm{IC}_{100}(7.4 \mu \mathrm{M})$ concentrations and in DMSO controls. p21 protein levels were then analyzed on days 2, 4 and 6 with Western blot. During treatment, 17 was renewed every $48 \mathrm{~h}$. Calnexin was used as an equal loading control.

expression correlated with the cytotoxicity induced by $\mathbf{1 7}$ (Fig. 3 and Table 1). Indeed, this correlation could be the result of the RXR $\gamma$ expression and senescent progenitor subtype described previously [22]. Therefore, we knocked down RXR $\alpha$ or $\operatorname{RXR} \gamma$ in the MCF7 cell line, and then treated the cells with $\mathbf{1 7}$. We specifically chose MCF7 cells, which were reported to be senescent progenitors, to demonstrate our hypothesis in a luminal type of breast cancer cell other than T47D.

\subsection{Response of RXR $\alpha$ and RXR $\gamma$ knocked-down MCF7 cells to $\mathbf{1 7}$}

MCF7 cells were transiently transfected with siRXR $\alpha$, siRXR $\gamma$ and scrambled siRNA as a control. The transfected cells were then treated with compound $\mathbf{1 7}$ and subjected to an SRB cytotoxicity assay (Fig. 4A). The efficiency of the knockdown was evaluated by RT-PCR in parallel with the SRB assay (Fig. 4B and C). RT-PCR results showed that the knockdown of RXR $\alpha$ was $70 \%$ achieved and that of RXR $\gamma$ was silenced totally. Silencing of RXR $\alpha$ had no effect on the proliferation of MCF7 cells, whereas RXR $\gamma$ induced significant cytotoxic action $(p<0.02)$. In addition, 17 was also cytotoxic when RXR $\alpha$ was knocked down. These results may suggest that compound $\mathbf{1 7}$ maintained its cytotoxic effect despite the absence of the RXR $\alpha$ receptor through other retinoid receptors. (Fig. 4C).

\subsection{Docking of compound $\mathbf{1 7}$ on $R X R \gamma$}

To gain more insight into the interaction between compound $\mathbf{1 7}$ and RXR $\alpha$ or RXR $\gamma$ at the molecular level, we performed smallmolecule docking studies with ligand-binding domains of human retinoic acid receptors RXR $\alpha$ (1FBY) and RXR $\gamma$ (2GL8) using Swissdock (Fig. 5Ai and $\mathrm{Bi}$ ) [32]. Then we docked retinoic acid (PDB id: REA) to RXR $\alpha$ and RXR $\gamma$ and structurally aligned it to RXR $\alpha \cdot 17$ and $\mathrm{RXR} \gamma \cdot \mathbf{1 7}$ to demonstrate the binding site orientation of $\mathbf{1 7}$ with respect to REA (Fig. 5Aii and Bii). The alignment shows that RXR $\gamma \cdot \mathbf{1 7}$ has more structural overlap than RXR $\alpha$. This observation further suggests that the cytotoxic effect of $\mathbf{1 7}$ may be due to its interaction with $\operatorname{RXR} \gamma$ and it can be further studied by molecular dynamics studies in parallel with in vitro direct binding assays.

\section{Discussion}

Retinoids have been reported to be involved in chemoprevention and chemotherapeutics in cancer [1,4-6]. Therefore, we examined the cytotoxic activities of newly synthesized 28 retinoids, including ATRA, on epithelial-origin breast, liver and colon cancer cells (Supplementary Table 1). Retinoids 6, 8, 10, 11, 17, 18, 24, 25, 26 and 27 had cytotoxic activities with $\mathrm{IC}_{50}$ values below
$10 \mu \mathrm{M}$ on all cancer cell types. Retinoid $\mathbf{1 7}$ had selective cytotoxicity on T-47D breast cancer cells but not on Huh7 liver and HCT116 colon cancer cells. Regarding the importance of the hormonal component of breast cancer, we focused on the molecular cytotoxicity analysis of retinoid $\mathbf{1 7}$ for a larger panel of breast cancer cells from different classes. We tested the cytotoxicity of retinoid derivatives on four Luminal A (CAMA-1, T-47D, MCF-7 and MDA-MB-361), one Luminal B (BT-474), three Triple-Negative-Basal (BT-20, MDA-MB157 and MDA-MB-231) and two HER2 (MDA-MB-453 and SK-BR3 ) subtypes of breast cancer cell lines (Table 1). Luminal $A$ is the most frequently diagnosed subtype, corresponding to $50-60 \%$ of all breast cancers. This subgroup represents estrogen receptor positivity. Generally, the luminal subgroup of breast cancer does not respond very well to traditional chemotherapy [36,37]; the major treatment for this group depends on hormone therapy, such as selective ER modulators (SERMs), like tamoxifen, and pure selective ER regulators, like fulvestrant. Another major challenge in hormone-positive breast cancer is de novo or acquired resistance to hormone therapy. Resistance to hormone therapies mostly occurs through the activation of signaling pathways that give input to cell cycle progression [38]. For this reason, there is a need for alternative targets and therapies for the hormone-resistant luminal group of breast cancer as well as for other hormone-negative breast cancer types. On the other hand, targeted therapies for triple-negative breast cancer (TNBC), which has a very poor prognosis and distant recurrence, are essential. Retinoids and differential activities of retinoid receptors in breast cancer cells have been previously studied [39]. The retinoid derivative AM580 is reported to be more active on RAR $\alpha$ than the pan-RAR ligand, ATRA. Furthermore, we also do not observe significant cell growth inhibition with ATRA (IC ${ }_{50}$ of 28.5-Supplementary Table 1) since ATRA does not bind to RXR. Similarly, some retinoid derivatives we tested on T-47D cells were active; some were inactive, indicating the selectivity of retinoids against RARs. As shown in Table 1, further cytotoxicity analysis of the most-active retinoid derivative, compound 17, successfully blocked the proliferation of luminal and TNBC cells at micromolar concentrations. Retinoid $\mathbf{1 7}$ had $\mathrm{IC}_{50}$ values of $3.71 \mu \mathrm{M}$ for T-47D Luminal A and $\mathrm{IC}_{50}$ values of $3.88 \mu \mathrm{M}$ for BT20 TNBC cells.

Our data also reveal that cell death induced by retinoid derivatives is senescence in breast cancer cells. ATRA's induction of senescence in liver cancer cells has been previously described as a p21-dependent mechanism for this cell death type [12]. Pan-retinoid ATRA or other retinoid derivatives' modes of action in inducing cell death is not clearly defined at the molecular level in breast cancer cells [39]. On the otherhand, the T-47D cell line has been grouped in a senescent cell progenitor (SCP) subtype and senescence occurrence has been reported to be associated with estrogen receptor loss and p21 accumulation in this cell line by our group [14]. In correlation with these findings, we demonstrated that compound $\mathbf{1 7}$ led to the accumulation of p21 and induced senescence response in this cell line. In parallel, at the end of day six, $\mathrm{Rb}$ levels had increased and $\mathrm{pRb}$ levels remained unchanged during senescence (data not shown). In conjunction with our results, ATRA has been shown to induce cell-cycle arrest through p21 overexpression in human monoblastic U-937 cells and liver cancer HepG2 cells, indicating the importance of retinoids in cancer therapy $[9,40]$. Recently, Lim et al. showed that ATRA causes senescence in HepG 2 hepatoma cells by upregulation of p16 and p21. They also observed RAR- $\beta 2$ involvement in this effect [12]. Our study with the retinoid derivative $\mathbf{1 7}$ on 11 different breast cancer cells and a comparative analysis of RAR and RXR gene expression reveal the importance of RXRs in breast cancer cell proliferation. RXR knockdown experiments using RXR $\alpha$ - and RXR $\gamma$-specific siRNAs in the presence or absence of retinoid derivative $\mathbf{1 7}$ showed not only the cell-survival-inhibitory effects of this compound but also 
$\mathbf{A}$

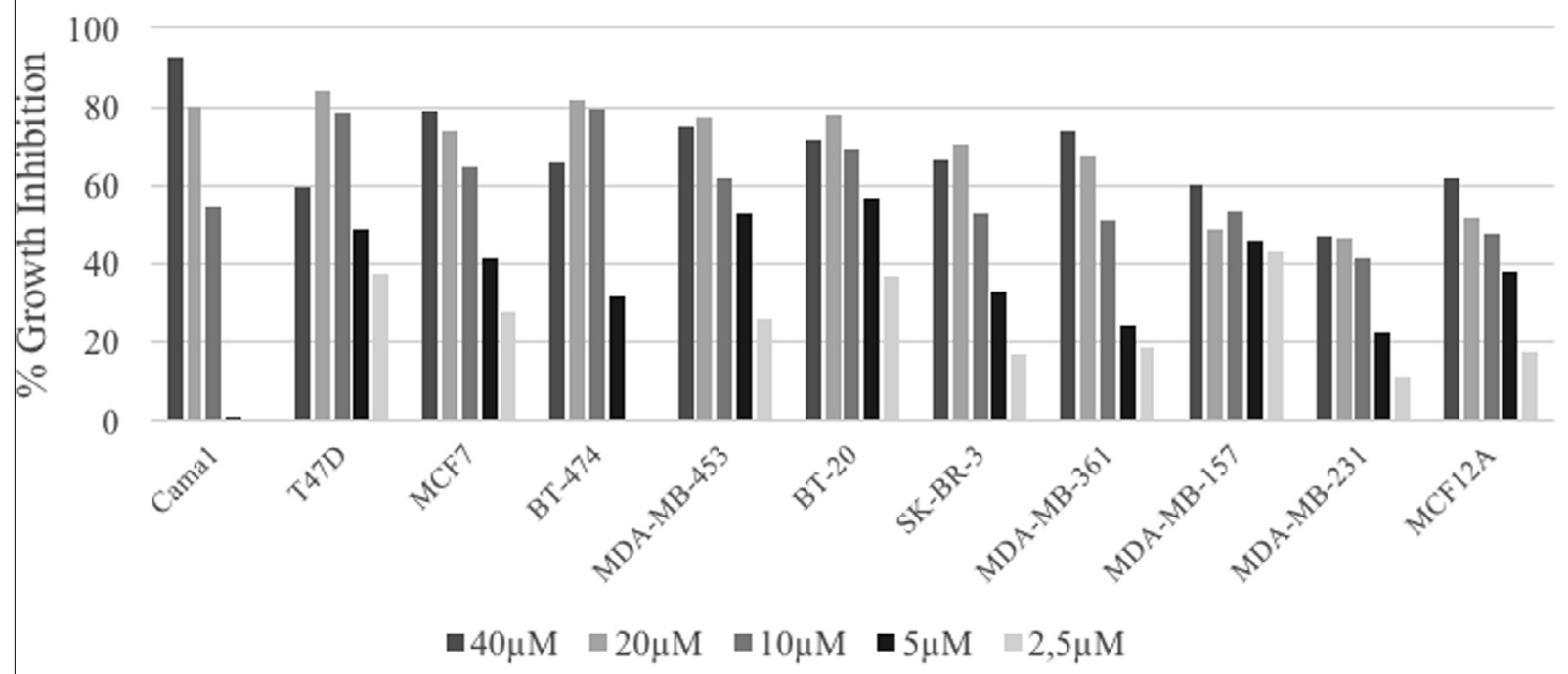

B

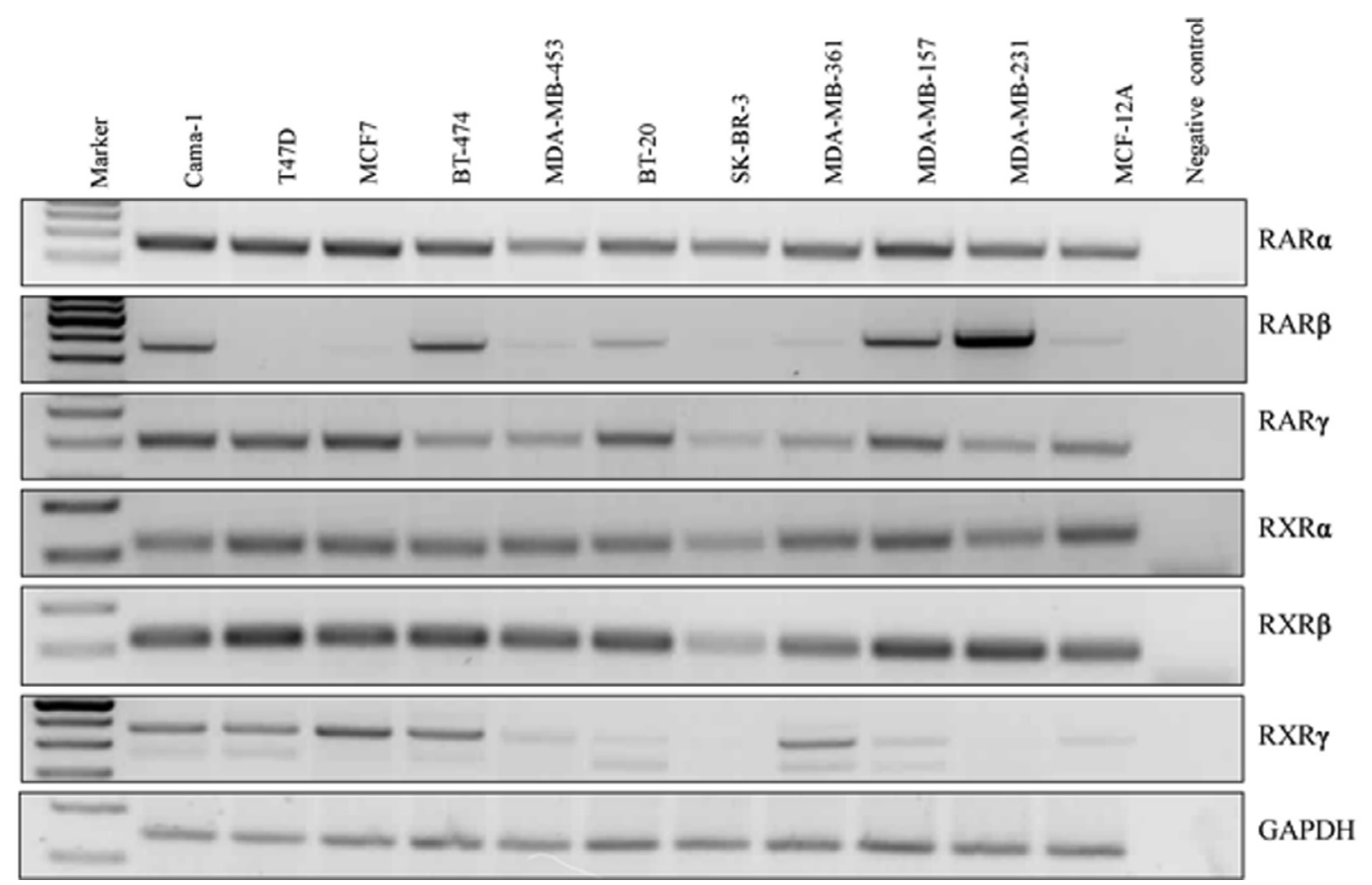

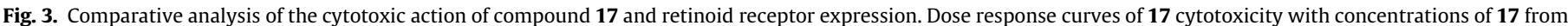

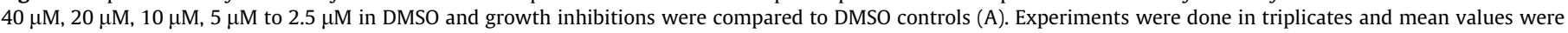

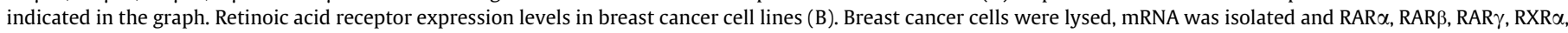
RXR $\beta$ and RXR $\gamma$ levels were determined using RT-PCR. GAPDH was used for a reference gene expression.

the importance of RXRs in breast cancer cell proliferation. While siRNA-mediated RXR $\alpha$ knockdown did not alter cell proliferation, $\mathrm{RXR} \gamma$ knockdown had a significant anti-proliferative effect on MCF7 cells. Compound 17, had a dramatic anti-proliferative activity on RXR $\alpha$ knockdown cells with normal RXR $\gamma$ expression, indicating that the major target of compound $\mathbf{1 7}$ can be RXR $\gamma$. However we were able to knockdown RXR $\alpha$ only by 70\% achieved which does not rule out that $\mathbf{1 7}$ does not target RXR $\alpha$ for its cytotoxic activity. Our initial docking analysis can be further investigated by molecular dynamics and direct in vitro binding assays. Similarly structurally modified two Pyrazine Arotinoid derivatives reported to be selectively differential activities on RAR and RXRs supporting the selectivity of retinoid derivatives against retinoid receptors $[41,42]$. Findings of this study showed that Retinoid X receptors could be associated with the anti-proliferative effects of retinoid derivative $\mathbf{1 7}$. We also demonstrated that RXR $\gamma$ expression down-regulation leads to a significant decrease in cell proliferation. Therefore, we suggest that retinoid derivative $\mathbf{1 7}$ and other retinoids that target $\mathrm{RXR} \gamma$, can be considered for breast cancer treatment in patients experiencing resistance to hormonal therapies. We submit that mechanisms underlying the regulation of Retinoid X receptors and small molecules' action on these proteins may merit further evaluation as a novel strategy against breast cancer. 

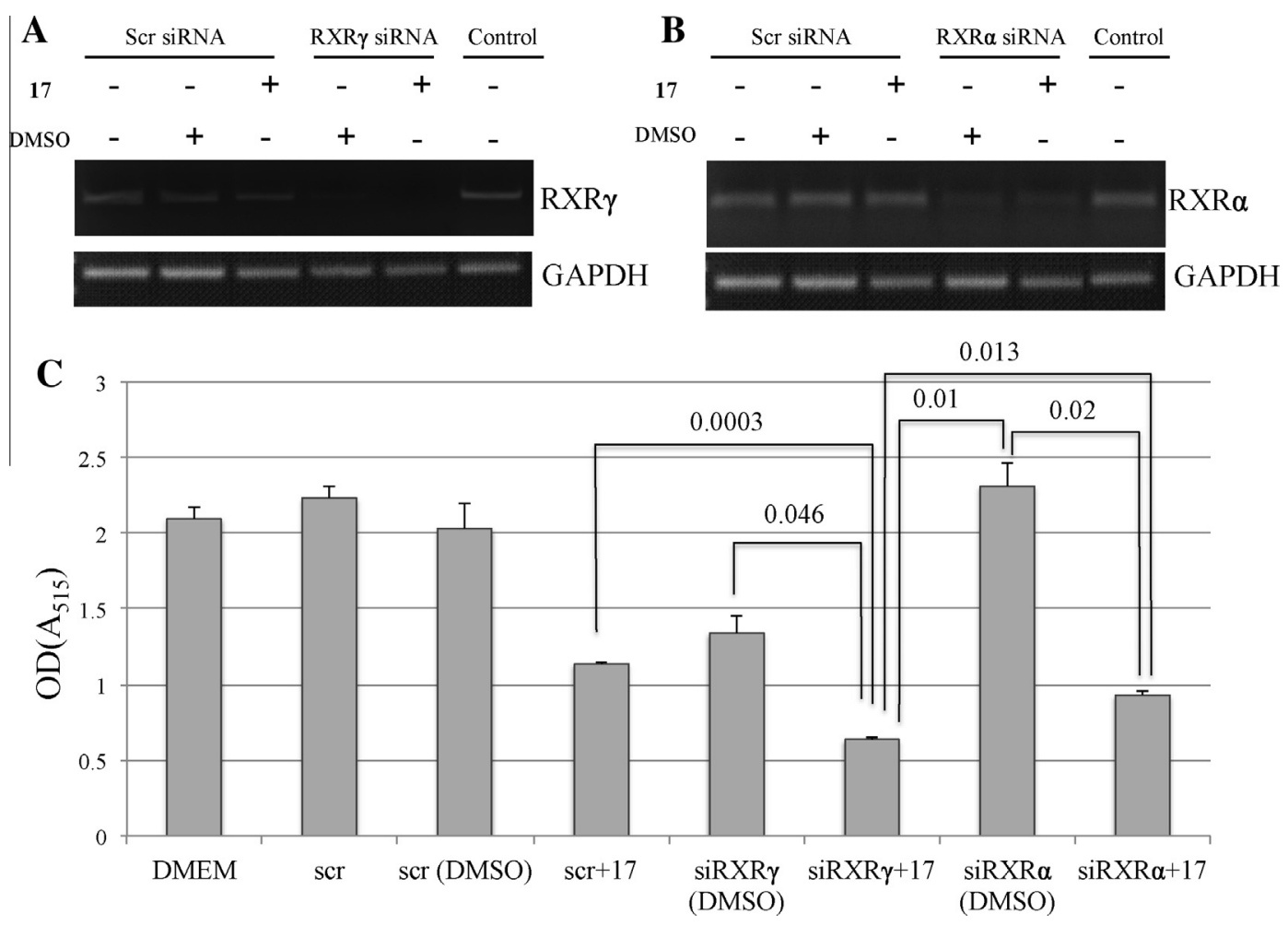

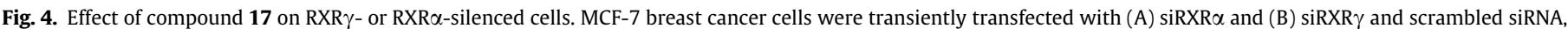

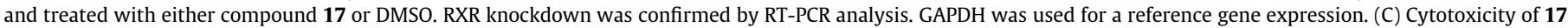

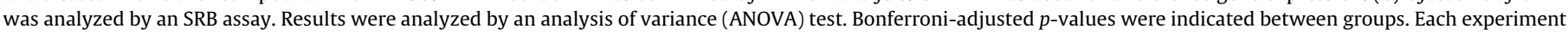
was done in triplicate.

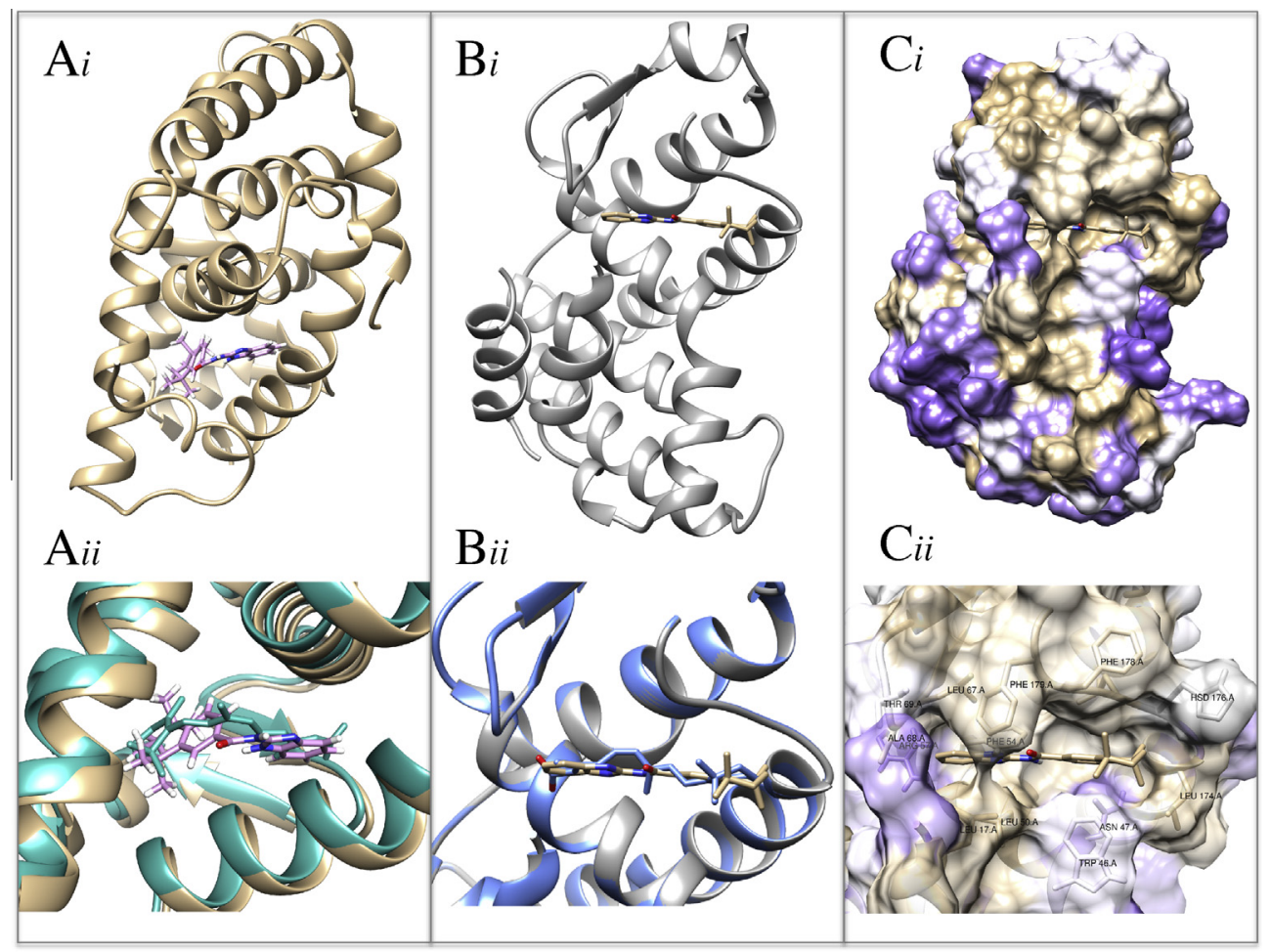

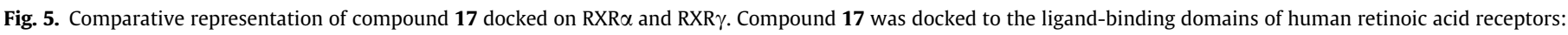

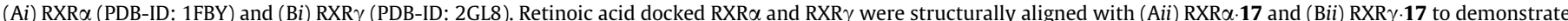

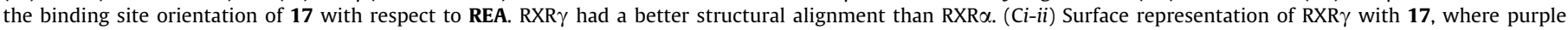
indicates the most-hydrophilic and tan-color indicates the most-hydrophobic regions. 


\section{Acknowledgements}

This work was supported by the Scientific and Technical Research Council of Turkey, TUBITAK (project \#106S359). We thank Ms. R. Nelson for editing the English of the final version of our manuscript.

\section{Appendix A. Supplementary data}

Supplementary data associated with this article can be found, in the online version, at http://dx.doi.org/10.1016/j.steroids.2016.02. 008.

\section{References}

[1] S.A. Ross, P.J. McCaffery, U.C. Drager, L.M. De Luca, Retinoids in embryonal development, Physiol. Rev. 80 (3) (2000) 1021-1054.

[2] P. Germain, P. Chambon, G. Eichele, R.M. Evans, M.A. Lazar, M. Leid, et al., International Union of Pharmacology. LX. Retinoic acid receptors, Pharmacol. Rev. 58 (4) (2006) 712-725.

[3] P. Germain, P. Chambon, G. Eichele, R.M. Evans, M.A. Lazar, M. Leid, et al., International Union of Pharmacology. LXIII. Retinoid X receptors, Pharmacol. Rev. 58 (2006) 760-772.

[4] X.-H. Tang, L.J. Gudas, Retinoids, retinoic acid receptors, and cancer, Annu. Rev. Pathol. 6 (2011) 345-364.

[5] D.R. Soprano, P. Qin, K.J. Soprano, Retinoic acid receptors and cancers, Annu. Rev. Nutr. 24 (2004) 201-221.

[6] E. Garattini, G. Paroni, M. Terao, Retinoids and breast cancer: new clues to increase their activity and selectivity, Breast Cancer Res. 14 (5) (2012) 111.

[7] K.J. Soprano, E. Purev, S. Vuocolo, D.R. Soprano, Rb2/p130 and protein phosphatase 2A: key mediators of ovarian carcinoma cell growth suppression by all-trans retinoic acid, Oncogene 25 (38) (2006) 5315-5325.

[8] B.D. Chang, E.V. Broude, M. Dokmanovic, H. Zhu, A. Ruth, Y. Xuan, et al., A senescence-like phenotype distinguishes tumor cells that undergo terminal proliferation arrest after exposure to anticancer agents, Cancer Res. 59 (15) (1999) 3761-3767.

[9] A. Dimberg, F. Bahram, I. Karlberg, L.-G. Larsson, K. Nilsson, F. Oberg, Retinoic acid-induced cell cycle arrest of human myeloid cell lines is associated with sequential down-regulation of c-Myc and cyclin E and posttranscriptional upregulation of p27(Kip1), Blood 99 (6) (2002) 2199-2206.

[10] L. Wang, J.P. Mear, C.-Y. Kuan, M.C. Colbert, Retinoic acid induces CDK inhibitors and growth arrest specific (Gas) genes in neural crest cells, Dev. Growth Differ. 47 (3) (2005) 119-130.

[11] B.D. Chang, K. Watanabe, E.V. Broude, J. Fang, J.C. Poole, T.V. Kalinichenko, et al., Effects of p21Waf1/Cip1/Sdi1 on cellular gene expression: implications for carcinogenesis, senescence, and age-related diseases, Proc. Natl. Acad. Sci. U.S.A. 97 (8) (2000) 4291-4296.

[12] S.-H. Park, J.S. Lim, K.L. Jang, All-trans retinoic acid induces cellular senescence via upregulation of p16, p21, and p27, Cancer Lett. 310 (2) (2011) 232-239.

[13] F. Bray, J.-S. Ren, E. Masuyer, J. Ferlay, Global estimates of cancer prevalence for 27 sites in the adult population in 2008, Int. J. Cancer 132 (5) (2013) 11331145.

[14] M. Mumcuoglu, S. Bagislar, H. Yuzugullu, H. Alotaibi, S. Senturk, P. Telkoparan, et al., The ability to generate senescent progeny as a mechanism underlying breast cancer cell heterogeneity, PLoS ONE 5 (6) (2010) e11288.

[15] W.Y. Zhu, C.S. Jones, A. Kiss, K. Matsukuma, S. Amin, L.M. De Luca, Retinoic acid inhibition of cell cycle progression in MCF-7 human breast cancer cells, Exp. Cell Res. 234 (2) (1997) 293-299.

[16] R. Mangiarotti, M. Danova, R. Alberici, C. Pellicciari, All-trans retinoic acid (ATRA)-induced apoptosis is preceded by G1 arrest in human MCF-7 breast cancer cells, Br. J. Cancer 77 (2) (1998) 186-191.

[17] L. Altucci, H. Gronemeyer, The promise of retinoids to fight against cancer, Nat. Rev. Cancer 1 (3) (2001) 181-193.

[18] M.A. Smith, B. Anderson, Where to next with retinoids for cancer therapy? Clin Cancer Res. 7 (10) (2001) 2955-2957.
[19] J.A. Fontana, A.K. Rishi, Classical and novel retinoids: their targets in cancer therapy, Leukemia 16 (4) (2002) 463-472.

[20] S. Zanardi, D. Serrano, A. Argusti, M. Barile, M. Puntoni, A. Decensi, Clinical trials with retinoids for breast cancer chemoprevention, Endocr. Relat. Cancer 13 (1) (2006) 51-68.

[21] M. Tuncbilek, E.B. Guven, T. Onder, Atalay R. Cetin, Synthesis of novel 6-(4substituted piperazine-1-yl)-9-( $\beta$-D-ribofuranosyl)purine derivatives, which lead to senescence-induced cell death in liver cancer cells, J. Med. Chem. 55 (7) (2012) 3058-3065.

[22] N. Ozturk, E. Erdal, M. Mumcuoglu, K.C. Akcali, O. Yalcin, S. Senturk, et al. Reprogramming of replicative senescence in hepatocellular carcinoma-derived cells, Proc. Natl. Acad. Sci. U.S.A. 103 (7) (2006) 2178-2183.

[23] L. Hayflick, P.S. Moorhead, The serial cultivation of human diploid cell strains, Exp. Cell Res. 25 (1961) 585-621.

[24] I. Ben-Porath, R.A. Weinberg, The signals and pathways activating cellular senescence, Int. J. Biochem. Cell Biol. 37 (5) (2005) 961-976.

[25] G.P. Dimri, What has senescence got to do with cancer?, Cancer Cell 7 (6) (2005) 505-512

[26] A.S. Gurkan, A.Z. Karabay, Z. Buyukbingol, E. Buyukbingol, Synthesis and effects of some novel tetrahydronaphthalene derivatives on proliferation and nitric oxide production in lipopolysaccharide activated Raw 264.7 macrophages, Eur. J. Med. Chem. 46 (2) (2011) 468-479.

[27] P. Skehan, R. Storeng, D. Scudiero, A. Monks, J. McMahon, D. Vistica, et al., New colorimetric cytotoxicity assay for anticancer-drug screening, J. Natl Cancer Inst. 82 (13) (1990) 1107-1112.

[28] R.H. Shoemaker, The NCI60 human tumour cell line anticancer drug screen, Nat. Rev. Cancer 6 (10) (2006) 813-823.

[29] G.P. Dimri, X. Lee, G. Basile, M. Acosta, G. Scott, C. Roskelley, et al., A biomarker that identifies senescent human cells in culture and in aging skin in vivo, Proc. Natl. Acad. Sci. U.S.A. 92 (20) (1995) 9363-9367.

[30] E.F. Pettersen, T.D. Goddard, C.C. Huang, G.S. Couch, D.M. Greenblatt, E.C Meng, et al., UCSF Chimera - a visualization system for exploratory research and analysis, J. Comput. Chem. 25 (13) (2004) 1605-1612.

[31] A. Grosdidier, V. Zoete, O. Michielin, Fast docking using the CHARMM force field with EADock DSS, J. Comput. Chem. (2011).

[32] A Grosdidier, V Zoete, O. Michielin, SwissDock, a protein-small molecule docking web service based on EADock DSS, Nucleic Acids Res. 39 (Web Server issue) (2011) W270-W277.

[33] J. Campisi, F. d'Adda di Fagagna, Cellular senescence: when bad things happen to good cells, Nat. Rev. Mol. Cell Biol. 8 (9) (2007) 729-740.

[34] H. Zhang, Molecular signaling and genetic pathways of senescence: its role in tumorigenesis and aging, J. Cell. Physiol. 210 (3) (2007) 567-574.

[35] Y.H. Chen, D. Lavelle, J. DeSimone, S. Uddin, L.C. Platanias, M. Hankewych, Growth inhibition of a human myeloma cell line by all-trans retinoic acid is not mediated through downregulation of interleukin-6 receptors but through upregulation of p21(WAF1), Blood 94 (1) (1999) 251-259.

[36] F. Bertucci, P. Finetti, N. Cervera, E. Charafe-Jauffret, M. Buttarelli, J. Jacquemier, et al., How different are luminal A and basal breast cancers?, Int J. Cancer 124 (6) (2009) 1338-1348.

[37] P. Eroles, A. Bosch, J.A. Pérez-Fidalgo, A. Lluch, Molecular biology in breast cancer: intrinsic subtypes and signaling pathways, Cancer Treat. Rev. 38 (6) (2012) 698-707.

[38] C.A. Lange, D. Yee, Killing the second messenger: targeting loss of cell cycle control in endocrine-resistant breast cancer, Endocr. Relat. Cancer 18 (4) (2011) C19-C24

[39] A. Bosch, S.P. Bertran, Y. Lu, A. Garcia, A.M. Jones, M.I. Dawson, et al., Reversal by RAR $\alpha$ agonist Am 580 of c-Myc-induced imbalance in RAR $\alpha / R A R \gamma$ expression during MMTV-Myc tumorigenesis, Breast Cancer Res. 14 (4) (2012) R121.

[40] J.S. Lim, S.-H. Park, K.L. Jang, All-trans retinoic acid induces cellular senescence by up-regulating levels of p16 and p21 via promoter hypomethylation, Biochem. Biophys. Res. Commun. 412 (3) (2011) 500-505.

[41] J. García, H. Khanwalkar, R. Pereira, C. Erb, J.J. Voegel, P. Collette, et al., Pyrazine arotinoids with inverse agonist activities on the retinoid and rexinoid receptors, ChemBioChem 10 (2009) 1252-1259.

[42] J.K. Furmick, I. Kaneko, A.N. Walsh, J. Yang, J.S. Bhogal, G.M. Gray, et al., Modeling, synthesis and biological evaluation of potential retinoid X receptorselective agonists: novel halogenated analogues of 4-[1-(3,5,5,8,8pentamethyl-5,6,7,8-tetrahydro-2-naphthyl)ethynyl]benzoic acid (bexarotene), ChemMedChem 7 (9) (2012) 1551-1566. 